\title{
Growth, Development and Natural Resources: New Evidence Using a Heterogeneous Panel Analysis
}

\author{
Tiago V. de V. Cavalcanti, Kamiar Mohaddes \\ and Mehdi Raissi
}

November 2009

CWPE 0946 


\title{
Growth, Development and Natural Resources: New Evidence Using a Heterogeneous Panel Analysis*
}

\author{
Tiago V. de V. Cavalcanti, Kamiar Mohaddes, and Mehdi Raissi \\ Faculty of Economics, University of Cambridge
}

November 4, 2009

\begin{abstract}
This paper explores whether natural resource abundance is a curse or a blessing. In order to do so, we firstly develop a theory consistent econometric model, in which we show that there is a long run relationship between real income, the investment rate, and the real value of oil production. Secondly, we investigate the long-run (level) effects of natural resource abundance on domestic output as well as the short-run (growth) effects. Thirdly, we make use of a non-stationary panel approach which explicitly estimates the long-run relationships from annual data as opposed to the dynamic and static panel approaches which might in fact estimate the high-frequency relationships. Fourthly, we account for cross-country dependencies that arise potentially from oil price shocks and other unobserved common factors, and allow countries to respond differently to these shocks. Finally, we explicitly recognize that there is a substantial heterogeneity in our sample, consisting of 53 oil exporting and importing countries with annual data between 1980-2006, and adopt the methodology developed by Pesaran (2006) for estimation. This approach considers different dynamics for each country and is consistent under both cross-sectional dependence and cross-country heterogeneity. We also check the robustness of these results by using the fully modified OLS method of Pedroni (2000). Our non-stationary approach also allows for country-specific unobserved factors, such as social and human capital, to be captured in the fixed effects and the heterogeneous trends together with any omitted factors. Our estimation results, using the real value of oil production, rent or reserves as a proxy for resource endowment, indicate that oil abundance is in fact a blessing and not a curse, exhibited through both the long-run and the short-run effects.
\end{abstract}

JEL Classifications: C23, O13, O40, Q32.

Keywords: Growth models, natural resource curse, cointegration, cross sectional dependence, common correlated effects, and oil.

${ }^{*}$ We gratefully acknowledge financial support from the Corporación Andina de Fomento (CAF). We are grateful to Hashem Pesaran as well as conference participants at the LACEA-LAMES 2009 for constructive comments and suggestions. We would also like to thank Peter Pedroni and Takashi Yamagata for making their codes available to us. 


\section{Introduction}

The aim of this paper is to investigate the following questions: Is an abundance of natural resources, in particular oil, a curse or a blessing? What are the effects of natural resource abundance on growth and economic development, as seen in the level of income per capita? Following the influential work by Sachs and Warner (1995), ${ }^{1}$ a growing empirical literature on and interest in the resource curse paradox was generated. According to this paradox, resource rich countries perform poorly when compared to countries which are not endowed with oil, natural gas, minerals and other non-renewable resources. Therefore, resource abundance is believed to be an important determinant of economic failure, which implies that oil abundance is a curse and not a blessing.

There are different explanations for why resource rich economies might be subject to this curse. Dutch disease (see Corden and Neary (1982), Neary and van Wijnbergen (1986), and Krugman (1987)) is one of the channels through which the resource curse makes itself felt: an increase in natural resource revenue leads to an appreciation of the real exchange rate, which negatively affects the profitability of the service and manufacturing sectors. The resulting re-allocation of resources from the high-tech and high-skill manufacturing and service sectors to the low-tech and low-skill natural resource sector is then harmful for economic growth. Another explanation for the resource curse paradox is based on rent-seeking theories, which argue that natural resource abundance generates an incentive for agents to engage in nonproductive activities and for the state to provide fewer public goods than the optimum. See for instance, Lane and Tornell (1996), Leite and Weidmann (1999), Tornell and Lane (1999), and Collier and Hoeffler (2004). Finally, Mehlum et al. (2006) have attempted to show that the impact of natural resources on growth and development depends primarily on institutions, while Boschini et al. (2007) have argued that the type of natural resources possessed is also an important factor. It is not our goal to discuss these theories in detail, or to determine their validity. We refer to Sachs and Warner (1995), Rosser (2006), and Caselli and Cunningham (2009) for an extensive examination of these prominent accounts of the natural resource curse paradox, as well as van der Ploeg and Venables (2009) for a more recent survey.

The empirical evidence on the resource curse paradox is rather mixed. Most papers in the literature tend to follow Sachs and Warner's cross-sectional specification introducing new explanatory variables for resource dependence/abundance, while others derive theoretical models that are loosely related to their empirical specification. Some of these papers confirm Sachs and Warner's results (see Rodriguez and Sachs (1999), Gylfason et al. (1999), and Bulte et al. (2005) among others). An important drawback of these studies with few exceptions, however, is their measure of resource abundance. Sachs and Warner (1995), for instance, use the ratio of primary-product exports to GDP in the initial period as a measure of resource abundance. This ratio, as clearly pointed out by Brunnschweiler and Bulte (2008), measures resource dependence rather than abundance. The latter should be introduced in the growth regressions as the stock or the flow of natural resources. Moreover, a cross sectional growth regression augmented with this regressor clearly suffers from endogeneity and omitted variable problems. Brunnschweiler and Bulte (2008) argue that the so-called

\footnotetext{
${ }^{1}$ See also Sachs and Warner (1997) and Sachs and Warner (2001).
} 
resource curse does not exist, and that while resource dependence, when instrumented in growth regressions, does not affect growth, resource abundance in fact positively affects economic growth. ${ }^{2}$ The positive effect of resource abundance on development and growth is also supported by Esfahani et al. (2009), who develop a long run growth model for a major oil exporting economy and derive conditions under which oil revenues are likely to have a lasting impact. However, this approach contrasts with the standard literature on "Dutch disease" and the "resource curse", which primarily focuses on the short run implications of a temporary resource discovery. On the other hand, Stijns (2005), using different measures for resource abundance, indicates that the effect of this variable on growth is ambiguous. Another branch of the literature investigates the channels through which natural resource abundance affects economic growth negatively. Gylfason (2001), for instance, shows that natural resource abundance appears to crowd out human capital investment with negative effects on the pace of economic activity, while Bravo-Ortega et al. (2005) show that higher education levels can in fact offset the negative effects of resource abundance. Therefore, it can be seen that the empirical findings on the resource curse paradox are still not conclusive.

There are a number of grounds on which the econometric evidence of the effects of resource abundance on growth may be questioned. Firstly, the literature relies primarily on a cross-sectional approach to test the resource curse hypothesis, and as such does not take into account the time dimension of the data. As noted above, the cross-sectional approach is also subject to endogeneity problems, and this is perhaps the most important reason for being skeptical about the econometric studies suggesting a positive or negative association between resource abundance and growth. Secondly, the vast majority of existing studies focus on the effects of resource abundance on the rate of economic growth, even though most models in the Solow/Ramsey tradition suggest that the effects on growth should be transitory, though permanent for the level of per capita income. ${ }^{3}$

In addition, even when panel data techniques are used most studies make use of homogeneous panel data approaches, such as the traditional fixed and random effects estimators, the instrumental variable (IV) technique proposed by Anderson and Hsiao (1981) and Anderson and Hsiao (1982), and the generalized methods of moments (GMM) model of Arellano and Bond (1991), Arellano and Bover (1995), among others. ${ }^{4}$ While homogeneous panel data models allow the intercepts to differ across groups all other parameters are constrained to be the same. Therefore, a high degree of homogeneity is still imposed. As discussed in Pesaran and Smith (1995), the problem with these dynamic panel data techniques, when applied to testing growth effects, is that they can produce inconsistent and potentially very misleading estimates of the average values of the parameters, since growth models typically exhibit substantial cross-sectional heterogeneity. In fact Lee et al. (1997), using a panel of data on 102 countries, illustrate that there is pervasive heterogeneity in speeds of convergence and in

\footnotetext{
${ }^{2}$ Arezki and van der Ploeg (2007) provide some support for these results as does Brunnschweiler (2009).

${ }^{3}$ This is also consistent with the empirical evidence provided by Klenow and Rodriguez-Clare (1997). In a different setting, Henry (2007) calls into question the usefulness of the cross-county approach to testing the relationship between capital account liberalization and growth. He argues that the capital deepening channel of gain from financial integration should imply only a temporary, rather than permanent, increase in growth, but most of the cross-sectional studies that have been conducted do not really test this.

${ }^{4}$ For a comprehensive survey of the econometric methods employed in the growth literature, and some of their shortcomings, see Durlauf et al. (2005) and Durlauf et al. (2009).
} 
growth rates across countries and show that the conventional method of imposing homogeneity are subject to substantial biases. In addition, Lee et al. (1998) test the null hypothesis of homogeneity in growth rates as well as the null of common speed of convergence and find that this is rejected for 102 non-oil countries. This pattern is the same for 61 intermediate group of countries, while for 22 OECD countries the null of common speed is not rejected. More recently Pedroni (2007) shows that there are significant differences in the aggregate production function technologies among countries. Taking into account these differences he argues that it is possible to explain the observed patterns of per capita income divergence across countries. Finally, the current econometric evidence does not address the problem of cross-sectional dependence arising from common factors or shocks. Thus estimations and inference based on models that do not take into account cross-country heterogeneity and dependence, such as the cross-sectional specifications widely used in the literature, can bring about biased and misleading results.

In this paper we take a different approach in order to test the resource curse hypothesis. We explicitly recognize that there is a substantial degree of heterogeneity in the growth experience of different resource abundant countries. We therefore use a heterogeneous panel data approach, which considers different dynamics for each country. We also account for cross-country dependencies that arise potentially from multiple common factors, and we allow the individual responses to these factors to differ across countries. A possible source of cross-sectional dependency might be due to world-wide common shocks that affect all cross-sectional units. Changes in technology and in the price of oil provide examples of such common shocks that may affect real GDP per capita, but to different degrees across countries. ${ }^{5}$ To address the issues raised above we adopt the common correlated effects estimator of Pesaran (2006), a sufficiently general and flexible econometric approach, which is consistent under both cross-section dependence and cross-country heterogeneity. Moreover, we investigate the long-run (level) effects of natural resource abundance on domestic output as well as the short-run (growth) effects through level and Error Correction Model (ECM) regressions. We also check the robustness of our long-run results by using the fully modified OLS method of Pedroni (2000). An advantage of our non-stationary approach is that the fixed effects and the heterogeneous trends capture country-specific unobserved factors, such as social and human capital, which are very difficult to measure or observe accurately. In addition, omitted variables that are either constant or evolve smoothly over time are absorbed into the country specific deterministic trend.

Furthermore, we develop a standard growth model that requires the use of natural resources as an input in the production of the consumption good. We view natural resources as a proxy for energy and power. We assume that agents can extract natural resources at a rate which is optimally determined, and rent them out to firms for production. In contrast to the literature on exhaustible natural resources and economic growth, for instance Dasgupta and Heal (1974), we assume that costly investment will enable new reserves to be found and old fields to be developed. It is important to emphasize that while we do not believe natural resources are limitless, oil production and more importantly viable reserves do seem to increase over the horizon we are investigating empirically. ${ }^{6}$ Finally, our theoretical model

\footnotetext{
${ }^{5}$ Different forms of cross section dependence are discussed and formally defined in Pesaran and Tosetti (2007).

${ }^{6}$ If natural resources in our model represent power and energy used in production, we can also view the
} 
suggests a long run relationship between per capita income, the investment rate and the real value of oil production per capita which we use as the basis of our empirical investigation.

In contrast to most studies in the literature, our panel cointegration estimation results, using the real value of oil production, rent and reserves as a proxy for resource abundance, indicate that oil abundance is in fact a blessing and not a curse. Estimating a panel error correction model, we also show that oil abundance has a significantly positive growth effect in the short run.

The plan of this paper is as follows. Section 2 develops the theory underlying our econometric model. In Section 3 we investigate the growths effects of resource abundance by employing a naive cross-sectional approach. Section 4 provides a brief review of our panel data model and the estimation methods employed. Section 5 reports the estimation results and Section 6 provides some concluding remarks.

\section{The Theoretical Model}

One of the major drawbacks of the empirical literature on growth and natural resource abundance, is the lack of theoretical derivation of the econometric model that is being tested. Either an ad hoc approach is used, in which output growth is regressed on a number of variables that are arbitrary chosen, or a theoretical model is developed but when it comes to estimation the econometric model is not connected to the theory derived restrictions. As part of this paper we put emphasis on developing a robust and consistent theory derived econometric model which can be directly tested.

Time is continuous and there is a continuum of identical firms of measure one. The representative firm uses physical capital, $K(t)$, labor, $L(t)$, and natural resources, $O(t)$, to produce the consumption good, $Y(t)$, according to the following production function:

$$
Y(t)=K(t)^{\alpha_{1}} O(t)^{\alpha_{2}}(A(t) L(t))^{1-\alpha_{1}-\alpha_{2}}, \alpha_{1}, \alpha_{2}>0, \alpha_{1}+\alpha_{2}<1,
$$

where $A(t)=A(0) e^{g t}$ is the labor augmenting technical progress, and $A(0)$ is an economyspecific initial endowment of technology. We could also include human capital as an input in production process but we abstract from this to simplify the analysis. In fact, in Section 4, we argue that our non-stationary panel approach allows us to capture both human capital, in the form of education, and social capital, in the form of social and political institutions, as these effects are absorbed by the fixed effects and the heterogeneous trends in our cointegrated panel specification, equation (16).

Let $r(t), p(t)$, and $w(t)$ denote the rental price of capital, natural resources, and labor. Competition implies that factors are remunerated according to their marginal productivity, such that:

$$
r(t)=\alpha_{1} \frac{Y(t)}{K(t)}, p(t)=\alpha_{2} \frac{Y(t)}{O(t)}, w(t)=\left(1-\alpha_{1}-\alpha_{2}\right) \frac{Y(t)}{L(t)} .
$$

Since the production function exhibits constant returns to scale, profits are zero, and firm ownership is not important.

increase in reserves as discovery of new energy sources. 
The economy is inhabited by a continuum of identical infinitely lived households with measure one. We can therefore work with a representative household, which grows at the exogenous rate, $n$, such that: $N(t)=N(0) e^{n t}$, and $N(0)$ is the initial endowment of labour. Each household member is endowed with a unit of productive time as well as $K(0)$, the initial level of capital stock. Capital is rented to firms for production of the consumption good and depreciates at rate $\delta$. Let $I^{K}(t)$ be investment in physical capital. Therefore:

$$
\dot{K}(t)=I^{K}(t)-\delta K(t) .
$$

Let $c(t)$ denote per capita household consumption with preferences defined as

$$
\int_{0}^{\infty} e^{-\rho t} N(t) u(c(t)) d t
$$

where $\rho>0$ is the subjective discount rate. The instantaneous utility function is given by:

$$
u(c)=\frac{c^{1-\theta}-1}{1-\theta}, \theta>0 .
$$

In addition to capital, households are also endowed with a stock of natural resources, $S(t)$, which can be extracted at rate $\gamma(t)$ and rented out to firms for the production of the consumption good. New reserves can be found and old fields can be developed, but this requires investment, $I^{S}(t)$, such that for each unit of investment households have to pay $\phi\left(\frac{I^{S}(t)}{S(t)}\right)$ units of output. We assume that this cost is convex, such that $\phi^{\prime}(\cdot) \geq 0$ and $\phi^{\prime \prime}(\cdot) \geq 0$, and that $\phi(0)=\phi^{\prime}(0)=0$. The evolution of the stock of natural resources is then given by

$$
\dot{S}(t)=-\gamma(t) S(t)+I^{S}(t),
$$

where the initial stock of natural resources, $S(0)$, is given. The problem of the representative household is to choose the path of consumption, $c$, natural resource extraction rate, $\gamma$, investment in natural resources, $I^{S}$, capital, $K$, and the stock of natural resources, $S$, so as to maximize ${ }^{7}$

$$
\begin{aligned}
\max \int_{0}^{\infty} e^{-\rho t} N u(c) d t & \text { subject to } \\
N c+\dot{K}+I^{S}\left(1+\phi\left(\frac{I^{S}}{S}\right)\right)= & w N+r K-\delta K+p \gamma S, \\
\dot{S}= & -\gamma S+I^{S}, \\
& c \geq 0, \gamma \geq 0, I^{S}>0 .
\end{aligned}
$$

Equation (3) corresponds to the household's budget constraint, and equation (5) states the constraint on the choice variables.

The current value Hamiltonian for this problem is then given by

$$
\begin{aligned}
H\left(t ; c, I^{S}, \gamma ; K, S ; \lambda, \mu\right)= & e^{-\rho t} N u(c)+\mu\left[I^{S}-\gamma S\right] \\
& +\lambda\left[w N+r K+p \gamma S-\delta K-N c-I^{S}\left(1+\phi\left(\frac{I^{S}}{S}\right)\right)\right],
\end{aligned}
$$

\footnotetext{
${ }^{7}$ For the sake of notation, we will abstract from the time indicator variable from here on.
} 
where $\lambda$ and $\mu$ are the costate variables for physical capital and the stock of natural resources respectively.

In equilibrium, we have that $O=\gamma S, L=N$, and:

$$
\begin{aligned}
& \lambda=e^{-\rho t} c^{-\theta} \Rightarrow \frac{\dot{\lambda}}{\lambda}=-\left(\rho+\theta \frac{\dot{c}}{c}\right), \\
& \rho+\theta \frac{\dot{c}}{c}=\alpha_{1} \frac{Y}{K}-\delta, \\
& \lambda\left[1+\phi\left(\frac{I^{S}}{S}\right)+\phi^{\prime}\left(\frac{I^{S}}{S}\right) \frac{I^{S}}{S}\right]=\mu \quad \Rightarrow \quad \lambda q^{S}=\mu \\
& \lambda p=\mu \quad \Rightarrow \quad \lambda \alpha_{2} \frac{Y}{\gamma S}=\mu, \\
& -\dot{\mu}=\phi^{\prime}\left(\frac{I^{S}}{S}\right)\left(\frac{I^{S}}{S}\right)^{2} \lambda, \\
& N c+\dot{K}+I^{S}\left[1+\phi\left(\frac{I^{S}}{S}\right)\right]=Y-\delta K, \\
& \dot{S}=-\gamma S+I^{S}, \\
& \lim _{t \rightarrow \infty} \lambda K=0, \text { and } \lim _{t \rightarrow \infty} \mu S=0 .
\end{aligned}
$$

Equations (6) and (7) correspond to the change in the shadow price of capital and the traditional Euler equation, respectively. Condition (8) states that the marginal cost of investment in natural resources is equal to its shadow value. Equation (9) is the condition on the rate of extraction, $\gamma$, and equation (10) defines the change in the shadow price of $S$. Equations (11) and (12) are the resource constraint and the evolution of the stock of natural resources, respectively. Finally, equation (13) defines the transversality conditions: one for physical capital and another for the stock of natural resources.

For any variable $X$, let's define variable $\tilde{x}=\frac{X}{e^{g^{*}} t}$, in which $g_{X}^{*}$ is the growth rate of variable $X$ along the balanced growth path, or the long-run equilibrium.

Proposition 1 Consider the above growth model and let $\phi^{\prime}(\cdot)>0, \phi^{\prime \prime}(\cdot) \geq 0$, and $\phi(0)=$ $\phi^{\prime}(0)=0$.

1. Then, there exists a non-zero balanced growth path equilibrium with $\tilde{k}^{*}>0, \tilde{y}^{*}>0$, $\tilde{o}^{*}>0, g_{\gamma}^{*}=0, g_{K}^{*}=g_{Y}^{*}=g_{S}^{*}=(n+g)$, and $g_{c}^{*}=g$.

2. In addition, if $p$ is determined in the world market, ${ }^{8}$ then this balanced growth path is saddle-path stable.

\section{Proof. See Appendix A}

Part one of proposition 1 suggests that along the balanced growth path, the rate of natural resource extraction is constant ${ }^{9}$ with the growth rate of both output and natural resources

\footnotetext{
${ }^{8}$ Which in fact is quite a plausible assumption.

${ }^{9}$ In a "cake-eating" problem of the optimal depletion of exhaustible resources, Dasgupta and Heal (1974) show that the optimal depletion rate is constant. See also Stiglitz (1974a) and Stiglitz (1974b).
} 
per capita equal to the technological progress, $g$. This implies that contrary to other models with exhaustible natural resources, our model does not imply a long run degenerated level of output. If oil can be imported or exported a similar balanced growth path equilibrium would hold.

Part two of proposition 1 states that if the price of the natural resource is determined in the international market, being exogenously given, then the non-zero balanced growth path equilibrium is saddle-path stable, which implies that there exists a one dimensional stable manifold converging to this long run equilibrium. ${ }^{10}$

Writing the production function (1) in terms of the steady state values of the variables in our model:

$$
\widetilde{y}_{t}^{*}=\left(\tilde{k}_{t}^{*}\right)^{\alpha_{1}}\left(\widetilde{o}_{t}^{*}\right)^{\alpha_{2}},
$$

or equivalently:

$$
\left(\widetilde{y}_{t}^{*}\right)^{1-\alpha_{1}}=\left(\frac{\tilde{k}_{t}^{*}}{\widetilde{y}_{t}^{*}}\right)^{\alpha_{1}}\left(\widetilde{o}_{t}^{*}\right)^{\alpha_{2}},
$$

we can use the equation of motion of capital to write the above as:

$$
\left(\widetilde{y}_{t}^{*}\right)^{1-\alpha_{1}}=\left(\frac{\frac{I_{t}^{K}}{Y_{t}}}{g+n+\delta}\right)^{\alpha_{1}}\left(\widetilde{o}_{t}^{*}\right)^{\alpha_{2}},
$$

and taking the natural logarithm we have:

$$
\left(1-\alpha_{1}\right) \ln {\widetilde{y_{t}}}^{*}=\alpha_{1} \ln \left(\frac{I_{t}^{K}}{Y_{t}}\right)-\alpha_{1} \ln (g+n+\delta)+\alpha_{2} \ln \widetilde{o}_{t}^{*},
$$

or equivalently in per capita terms

$$
\begin{aligned}
\ln y_{t}= & \frac{\left(1-\alpha_{1}-\alpha_{2}\right)}{\left(1-\alpha_{1}\right)} \ln A_{0}-\frac{\alpha_{1}}{\left(1-\alpha_{1}\right)} \ln (g+n+\delta) \\
& +\frac{\left(1-\alpha_{1}-\alpha_{2}\right)}{\left(1-\alpha_{1}\right)} g t+\frac{\alpha_{1}}{\left(1-\alpha_{1}\right)} \ln \left(\frac{I_{t}^{K}}{Y_{t}}\right)+\frac{\alpha_{2}}{\left(1-\alpha_{1}\right)} \ln o_{t},
\end{aligned}
$$

where lower case letters denote variables in per capita terms. Equation (14) is thus the key empirical reduced form equation, which states that there is an equilibrium relationship between real gross domestic product (GDP) per capita, the share of capital investment in real GDP, and the real value of natural resource (oil) production per capita. In fact this equilibrium relation is consistent with any long-run model in which oil production to income ratio is positive.

\section{Cross-sectional Estimation}

Before we proceed with testing our theory-derived econometric model, we employ a standard cross-sectional estimation technique based on Sachs and Warner (1995) to investigate the

\footnotetext{
${ }^{10}$ If the price of the natural resource is determined in the domestic market, then we cannot guarantee that the balanced growth path equilibrium is saddle path stable.
} 
growth effects of resource abundance. In order to do so, we estimate the following equation:

$$
g_{y, j}=\varsigma_{0}+\varsigma_{1} \ln y_{80, j}+\varsigma_{2} \bar{I}_{j}+\varsigma_{3} \ln \bar{o}_{j}+\xi_{j},
$$

where $g_{y, j}$ is the average growth rate of the Gross Domestic Product per capita between 1980 and 2006 for country $j=1 \ldots, J$, and $\ln y_{80, j}$ is the logarithm of the initial GDP per capita (in 1980). $\overline{I / Y}$ is the average investment share of GDP and $\ln \bar{o}_{j}$ is the logarithm of the average real value of oil production per capita between 1980 and 2006 . We also estimate equation (15) by replacing $\ln \bar{o}_{j}$, with the average of real oil rent per capita, $\ln \overline{o r}_{j}$, and the average real value of oil reserves per capita, $\ln \bar{s}_{j}$, between 1980 and 2006 .

Table 1: Cross-sectional "Naive" Estimation Results 1980-2006

\begin{tabular}{|l|c|c|c|}
\hline$g_{y, j}$ & $(i)$ & $(i i)$ & $(i i i)$ \\
\hline $\ln y_{80, j}$ & -0.07 & -0.06 & -0.06 \\
$\bar{I}_{j} Y_{j}$ & $(0.149)$ & $(0.148)$ & $(0.148)$ \\
$\ln \bar{o}_{j}$ & $0.23^{* * *}$ & $0.23^{* * *}$ & $0.23^{* * *}$ \\
$\ln \overline{o r}_{j}$ & $-0.18^{* *}$ & $(0.048)$ & $(0.049)$ \\
$\ln \bar{s}_{j}$ & - & $-0.18^{* *}$ & - \\
\hline Observations & 53 & - & - \\
\hline$R^{2}$ & 0.34 & 0.33 & $-0.18^{* *}$ \\
& - & - & 52 \\
\hline
\end{tabular}

Notes: Method of estimation is Ordinary Least Squares. The dependent variable is the average growth rate of GDP per capita between 1980 and 2006, $g_{y, j}$. Constants are included in all regressions but not reported. $(i)$ is estimated using ln $o_{j t}$, whereas (ii) and (iii) are estimated replacing $\ln o_{j t}$ with $\ln o r_{j t}$ and $\ln s_{j t}$ respectively. Standard errors are given in parenthesis. Symbols denote $* 10 \%, * * 5 \%, * * * 1 \%$ rejections.

The estimation results of the three cross-sectional specifications are reported in Table $1 .{ }^{11}$ While the coefficients of the investment share are significantly positive, the estimated values for the three measures of resource abundance are all statistically significant and negative, thus suggesting that the resource curse is present for the countries in our sample. However, this naive estimation procedure, as discussed in the introduction, is subject to omitted variable problems. The econometric specification above also imposes a large degree of homogeneity on the coefficients of interest and does not take into account the time dimension of the data. Given these observations, we employ the estimation procedure developed by Pesaran (2006) and applied in Holly et al. (2009) to see whether the resource curse is in fact present in our sample or whether this naive estimation procedure, as employed in the literature to support the existence of the resource curse, leads to possibly misleading conclusions.

\section{The Econometric Model and Methodology}

Our theoretical model, derived in Section 2, suggested a long run relationship between real gross domestic product (GDP), the investment share of GDP, and oil production. Using

\footnotetext{
${ }^{11}$ We also estimated (15) using data on the levels of the three oil abundance variables and obtained similar results as reported in Table 1, with the coefficient of oil in each specification being significantly negative.
} 
equation (14) we can write a panel model for oil producing countries, both net exporters and importers, as an equilibrium relationship compatible with the long-run theory developed:

$$
\ln y_{j t}=a_{j}+d_{j} t+\beta_{j 1} \ln (I / Y)_{j t}+\beta_{j 2} \ln o_{j t}+u_{j t}
$$

where $\ln y_{j t}$ is the logarithm of real GDP per capita for countries $j=1, \ldots, J$ and time periods $t=1, \ldots, T$. Likewise $\ln o_{j t}$ is the logarithm of real value of oil production per capita and $\ln (I / Y)_{j t}$ is log of the investment share of GDP over the same countries and time periods, with $a_{j}$ denoting country specific fixed effects and $d_{j} t$ representing heterogeneous country specific deterministic trends. Two features of the above long-run relation is worth noting; while in the augmented Solow and Ramsey models the parameters $\alpha_{1}$ and $\alpha_{2}$ in (1) are traditionally taken to be common across all countries, we do not impose this restriction as this is a feature of the model that we wish to investigate. This is also clear from our econometric model (16) in which the parameter vector of the slope coefficients, $\boldsymbol{\beta}_{j}=\left(\beta_{j 1}, \beta_{j 2}\right)^{\prime}$, is allowed to be heterogeneous across countries. Similarly, we do not impose homogeneity of the depreciation rate, $\delta_{j}$, or the growth rates of labour, $n_{j}$, and technology, $g_{j}$, which is accommodated through the fixed effects and the deterministic trends.

While (16) defines the theory derived long-run relation for oil producing countries, the short-run dynamics and their adjustment to the long-run across countries are accommodated through the error term, $u_{j t}$, which we assume has the following multi-factor error structure:

$$
u_{j t}=\boldsymbol{\tau}_{j}^{\prime} \mathbf{f}_{t}+\varepsilon_{j t}
$$

where $\mathbf{f}_{t}$ is a vector of unobserved common shocks, which can be stationary or nonstationary (see Kapetanios et al. (2006)) and are allowed to be serially correlated and possibly correlated with the logarithm of the investment share, $\ln (I / Y)_{j t}$, as well as oil production, $\ln \left(o_{j t}\right)$. The individual-specific errors, $\varepsilon_{j t}$, are allowed to be serially correlated over time and weakly dependent across countries, but are assumed to be distributed independently of both the regressors and the unobserved common factors.

Following Pesaran (2006), assuming a random coefficient model, $\boldsymbol{\beta}_{j}=\boldsymbol{\beta}+\varpi_{j}$, where $\varpi_{j} \sim I I D\left(\mathbf{0}, \mathbf{V}_{\varpi}\right)$, we focus on the estimation of the average value of $\boldsymbol{\beta}_{j}$. To eliminate cross sectional dependence (CD) asymptotically, both strong and weak forms, we make use of the Common Correlated Effects (CCE) type estimators developed by Pesaran (2006). One of the estimators pools observations over the cross sectional units and is called the CCE pooled (CCEP) estimator. If the share of capital in output, $\alpha_{j 1}$, and the share of oil in output, $\alpha_{j 2}$, are the same across countries, thus implying that the individual country slope coefficients, $\boldsymbol{\beta}_{j}$, are the same, then efficiency gains from pooling observations can be achieved. The other estimator, CCE mean group (CCEMG) estimator, is just a simple average of the individual country CCE estimators given by:

$$
\widehat{\boldsymbol{\beta}}_{C C E M G}=J^{-1} \sum_{j=1}^{J} \widehat{\boldsymbol{\beta}}_{j}
$$

Although our econometric specification is simple it is also very general. For instance, as opposed to the traditional cross-sectional and/or homogenous panel approaches in which one needs to find quantifiable variables that can act as proxies for unobserved factors, in our 
non-stationary panel approach the country specific determinstics, $a_{j}$ and $d_{j} t$, capture a broad class of those variables. In addition, the unobserved common components of $u_{j t}$ absorb a number of different factors that drive real income but are at the same time difficult to measure accurately. Moreover, any omitted variables that are either constant or evolve smoothly over time are also absorbed into the country specific fixed effects and the heterogeneous trend components. Furthermore, although our theoretical model does not include human capital, in the form of education, or social capital, in the form of social and political institutions, these unobserved and difficult to measure factors are in fact captured by $a_{j}$ and $d_{j} t$ in our cointegrated panel specification, see Pedroni (2007). Finally, another advantage of our non-stationary panel approach is that we explicitly estimate the long-run (low-frequency) relationships among the variables, using annual data rather than trying to take 5-year averages to filter out business cycle fluctuations common in the growth literature. This is in contrast to the traditional stationary dynamic and static panel approaches which might inadvertently uncover high-frequency relationships, see Durlauf and Quah (1999). The estimators are also superconsistent under cointegration and are robust to the omission of variables that are not part of the equilibrium relation defined in equation (14).

\section{$5 \quad$ Empirical Results}

To empirically test our theoretical model we obtain annual data from 1980 to 2006 on the logarithm of the real gross domestic product per capita, $y_{j t}$, the logarithm of the investment share of real GDP, $\ln (I / Y)_{j t}$, and the logarithm of the real value of oil production per capita, $\ln o_{j t}$. As we assume, but also prove, in Section 2 that oil production is a constant fraction, $\gamma^{*}$, of the total stock of oil reserves available, we are able to perform robustness check by estimating our econometric model (16) with the real value of oil reserves per capita, $\ln s_{j t}$, instead of $\ln o_{j t}$. As we also have access to data on oil rent for different countries a further robustness check is performed replacing $\ln o_{j t}$ with the real value of oil rent per capita, $\ln$ or $_{j t}$. Our data set covers 53 countries, see Table 9, the number for which oil production and rent data is available. As we do not have oil reserve data for Hungary, we estimate the equation with $\ln s_{j t}$ (also later referred to as specification $($ iii)) using the remaining 52 countries. Out of the 53 countries included in our sample 10 belong to the Organization of the Petroleum Exporting Countries (OPEC), but our sample also includes 17 out of the 30 OECD countries. As such there is a large degree of heterogeneity across countries. These 53 countries together cover 85 percent of world GDP, 77 percent of world oil production per day, and 81 percent of world proven oil reserves. Thus our sample is very comprehensive. A more detailed description of our data and their sources are provided in the Appendix B.

\subsection{Panel Unit Root Test Results}

Before we proceed with estimation of our model we need to test for cross sectional dependence of the errors and to consider the unit root properties of the variables in our model. It is important to make sure that we do not work with a mixture of $I(1)$ and $I(2)$ variables so that we make sensible interpretation of the long-run relationships. We start by looking at the CD (Cross-section Dependence) test of Pesaran (2004), which tends to a normal distribution 
as the number of countries tend to infinity, and is based on the average of the pair-wise correlations of the OLS residuals from the individual regressions of (16) in the panel. Table 2 reports the cross sectional dependence of the residuals from the $\operatorname{ADF}(p)$ regressions of the logs of real GDP per capita, investment share of GDP, as well as the real value of oil production, rent, and reserves and their lagged differences, over the period 1980 to 2006 across all of the 53 countries. For each $p=0,1,2$, and 3, the reported CD statistics are highly significant, with the three oil related variables displaying very large test statistics. The presence of the cross sectional dependence implies that the use of standard panel unit root tests, such as the test proposed by Im et al. (2003), from now on the IPS test, are not valid.

\section{Table 2: CD Test Statistics of ADF(p) Regressions}

\begin{tabular}{|c|c|c|c|c|}
\hline \multicolumn{5}{|c|}{ With an Intercept } \\
\hline & $A D F(0)$ & $A D F(1)$ & $A D F(2)$ & $\mathrm{ADF}(3)$ \\
\hline $\ln y_{j t}$ & 12.32 & 12.11 & 10.25 & 8.93 \\
\hline $\ln (I / Y)_{j t}$ & 3.48 & 3.16 & 3.17 & 2.86 \\
\hline $\ln o_{j t}$ & 131.72 & 131.23 & 129.80 & 129.10 \\
\hline $\ln o r_{j t}$ & 140.50 & 140.06 & 138.87 & 138.28 \\
\hline $\ln s_{j t}$ & 100.90 & 100 & 99.21 & 96.90 \\
\hline$\Delta \ln y_{j t}$ & 10.49 & 9.73 & 8.12 & 8.37 \\
\hline$\Delta \ln (I / Y)_{j t}$ & 3.89 & 3.62 & 3.21 & 3.60 \\
\hline$\Delta \ln o_{j t}$ & 137.49 & 135.20 & 133.76 & 132.10 \\
\hline$\Delta \ln o r_{j t}$ & 146.59 & 144.33 & 143.12 & 141.30 \\
\hline$\Delta \ln s_{j t}$ & 103.68 & 103.49 & 101.14 & 100.79 \\
\hline \multicolumn{5}{|c|}{ With an Intercept and a Linear Trend } \\
\hline & $A D F(0)$ & $A D F(1)$ & $A D F(2)$ & $\operatorname{ADF}(3)$ \\
\hline $\ln y_{j t}$ & 10.52 & 9.85 & 8.63 & 8.36 \\
\hline $\ln (I / Y)_{j t}$ & 3.47 & 3.32 & 3.39 & 3.06 \\
\hline $\ln o_{j t}$ & 135.42 & 133.64 & 129.79 & 128.34 \\
\hline $\ln o r_{i t}$ & 144.70 & 143.10 & 139.68 & 138.54 \\
\hline $\ln s_{i t}$ & 101.92 & 100.36 & 95.89 & 93.61 \\
\hline
\end{tabular}

Notes: $p^{t h}$-order Augmented Dickey-Fuller test statistics, $\operatorname{ADF}(p)$, for $\ln y_{j t}, \ln (I / Y)_{j t}, \ln o_{j t}, \ln o r_{j t}$ and $\ln s_{j t}$ are computed for each cross section unit separately in two cases (i) with an intercept only and (ii) with an intercept and a linear time trend. $C D=\sqrt{2 T / J(J-1)} \sum_{j=1}^{J-1} \sum_{k=j+1}^{J} \hat{\rho}_{j k}$, with $\hat{\rho}_{j k}$ being the correlation coefficient of the $\operatorname{ADF}(p)$ regression residuals between $j^{t h}$ and $k^{t h}$ cross section units, tends to $N(0,1)$ under the null hypothesis of no error cross section dependence. For more details see Pesaran (2004).

Given the above results, to perform panel unit root tests we will make use of Pesaran's CIPS test. This test follows the CCE approach and filters out the cross section dependence by augmenting the ADF regressions carried out separately for each country with cross section averages. The cross sectional augmented ADF (CADF) statistics are reported in Table 3 for different lag orders, from which it is clear that for all of our variables including investment shares, ${ }^{12}$ at the log-level and with or without a trend, the unit root hypothesis cannot be rejected at the 5 percent level, and for most variables not even at the 10 percent level. On the

\footnotetext{
${ }^{12}$ As Pedroni (2007) notes the investment to income ratio can only be locally nonstationary. It is naturally bounded as a ratio between zero and one, but for purposes of estimation in a dynamic cointegrating panel, local nonstationarity is a helpful property.
} 
other hand the unit root hypothesis is clearly rejected when applied to the first differences of these variables. Thus we can safely regard all the variables as being $I(1)$ and not worry about dealing with a mixture of $I(1)$ and $I(2)$ variables in our model.

\section{Table 3: Pesaran's CIPS Panel Unit Root Test Results}

\begin{tabular}{|l|c|c|c|c|}
\hline \multicolumn{5}{|c|}{ With an Intercept } \\
\hline & $C A D F(0)$ & $C A D F(1)$ & $C A D F(2)$ & $C A D F(3)$ \\
\hline $\ln y_{j t}$ & -1.808 & $-2.109^{*}$ & -1.969 & -1.914 \\
\hline $\ln (I / Y)_{j t}$ & -1.668 & $-2.042^{*}$ & -1.876 & -1.686 \\
\hline $\ln o_{j t}$ & -1.549 & -1.640 & -1.624 & -1.580 \\
\hline $\ln o r_{j t}$ & -1.532 & -1.587 & -1.576 & -1.517 \\
\hline $\ln s_{j t}$ & -1.905 & -1.837 & -1.542 & -1.576 \\
\hline$\Delta \ln y_{j t}$ & $-3.426^{* * *}$ & $-2.808^{* * *}$ & $-2.39^{* * *}$ & $-2.493^{* * *}$ \\
\hline$\Delta \ln (I / Y)_{j t}$ & $-3.925^{* * *}$ & $-3.226^{* * *}$ & $-2.828^{* * *}$ & $-2.551^{* * *}$ \\
\hline$\Delta \ln o_{j t}$ & $-4.231^{* * *}$ & $-2.999^{* * *}$ & $-2.700^{* * *}$ & $-2.125^{* *}$ \\
\hline$\Delta \ln o r_{j t}$ & $-4.282^{* * *}$ & $-3.020^{* * *}$ & $-2.726^{* * *}$ & $-2.151^{* *}$ \\
\hline$\Delta \ln s_{j t}$ & $-4.808^{* * *}$ & $-3.424^{* * *}$ & $-2.512^{* * *}$ & -2.022 \\
\hline \multicolumn{5}{|c|}{ With an Intercept and a Linear Trend } \\
\hline $\ln y_{j t}$ & $C A D F(0)$ & $C A D F(1)$ & $C A D F(2)$ & $C A D F(3)$ \\
\hline $\ln (I / Y)_{j t}$ & -1.949 & $-2.561^{*}$ & -2.514 & $-2.581^{*}$ \\
\hline $\ln o_{j t}$ & -1.827 & -2.332 & -2.215 & -2.071 \\
\hline $\ln o r_{j t}$ & -2.127 & -1.994 & -2.093 & -2.028 \\
\hline $\ln s_{j t}-2.159$ & -1.991 & -2.108 & -2.021 \\
\hline & -2.528 & -2.281 & -1.932 & -1.791 \\
\hline
\end{tabular}

Notes: The reported values are CIPS $(p)$ statistics, which are cross section averages of Cross-sectionally Augmented DickeyFuller $(\operatorname{CADF}(p))$ test statistics, for more details see Pesaran (2007). The relevant lower 1, 5, and 10 percent critical values for the CIPS statistics are $-2.23,-2.11$, and -2.04 with an intercept case, and $-2.73,-2.61$, and -2.54 with an intercept and a linear trend case, respectively. Symbols denote $* 10 \%, * * 5 \%, * * * 1 \%$ rejections.

\subsection{Panel Level Effects}

Having established that all of our variables are $I(1)$, we proceed by estimating the following equation:

$$
\ln y_{j t}=a_{j}+d_{j} t+\beta_{j 1} \ln (I / Y)_{j t}+\beta_{j 2} \ln o_{j t}+u_{j t}
$$

which we label as $(i)$, but as previously discussed we also estimate the above equation by replacing $\ln o_{j t}$ with $\ln o r_{j t},(i i)$, and $\ln s_{j t},(i i i) .{ }^{13}$ The results for the three specifications, $(i)$ to $(i i i)$, are shown in Table 4. It is clear that the coefficient of oil in all of our specifications is significantly positive and thus in line with our theoretical model, implying that oil abundance leads to a positive level effect. The first three columns report the mean group (MG) estimates, which do not take into account the unobserved common factors. While the estimates suggest similar coefficients on the investment share, those of the real value of oil production and rent are considerably smaller compared to the common correlated effects mean group (CCEMG) estimates, although not far from the common correlated effects pooled (CCEP) estimates.

\footnotetext{
${ }^{13}$ Recall that $o_{j t}$ denotes the per capita real value of oil production, while $o r_{j t}$ and $s_{j t}$ stand for the per capita value of oil rent and oil reserves respectively.
} 
Not surprisingly there is also evidence of cross sectional dependence for the MG estimation errors. For the CCEP and CCEMG estimations we augment (18) with the simple cross sectional averages of all of our regressors. From the CD test statistics it is clear that this augmentation has lead to reduction of cross sectional dependence, to such extent that we cannot reject at the 10 percent level the null of no cross sectional dependence for either of the two CCE type estimators. The last three columns report the CCEP estimates which have smaller coefficients on all of the variables as compared to the MG estimates. Finally, the CCEMG estimates have significantly larger coefficients on both the investment share of output and the oil variables considered as compared to the CCEP estimates. We argue that while the countries in our data set all produce oil, there are substantial heterogeneity among them: some countries are net exporters while others are net importers of oil; some are developed others are developing; in addition, they have different geographical locations. Given this level of heterogeneity across countries we focus on the results of the CCEMG estimates which are reported in the three columns in the middle of Table 4.

\section{Table 4: Estimation Results 1980-2006}

\begin{tabular}{|c|c|c|c|c|c|c|c|c|c|}
\hline $\ln y_{j t}$ & \multicolumn{3}{|c|}{ MG } & \multicolumn{3}{|c|}{ CCEMG } & \multicolumn{3}{|c|}{ CCEP } \\
\hline $\ln (I / Y)_{j t}$ & $\begin{array}{c}0.21^{* * *} \\
(0.024)\end{array}$ & $\begin{array}{c}0.22^{* * *} \\
(0.024)\end{array}$ & $\begin{array}{c}0.22^{* * * *} \\
(0.025)\end{array}$ & $\begin{array}{c}0.21^{* * * *} \\
(0.023)\end{array}$ & $\begin{array}{c}0.21^{* * *} \\
(0.023)\end{array}$ & $\begin{array}{c}0.19^{* * * *} \\
(0.024)\end{array}$ & $\begin{array}{c}0.15^{* * * *} \\
(0.022)\end{array}$ & $\begin{array}{c}0.15^{* * * *} \\
(0.021)\end{array}$ & $\begin{array}{c}0.15^{* * * *} \\
(0.023)\end{array}$ \\
\hline $\ln o_{j t}$ & $\begin{array}{c}0.06^{* * *} \\
(0.015)\end{array}$ & - & - & $\begin{array}{c}0.15^{* * *} \\
(0.031)\end{array}$ & - & - & $\begin{array}{c}0.06^{* * *} \\
(0.014)\end{array}$ & - & - \\
\hline $\ln o r_{j t}$ & - & $\begin{array}{c}0.05^{* * *} \\
(0.013)\end{array}$ & - & & $\underset{(0.033)}{0.14^{* * *}}$ & - & & $\begin{array}{c}0.06^{* * * *} \\
(0.014)\end{array}$ & - \\
\hline $\ln s_{j t}$ & - & - & $\begin{array}{c}0.05^{* * *} \\
(0.014)\end{array}$ & & - & $\begin{array}{l}0.04^{*} \\
(0.021)\end{array}$ & & - & $\begin{array}{l}0.01^{*} \\
(0.007)\end{array}$ \\
\hline CD Test Statistics & 3.23 & 3.35 & 2.43 & 1.59 & 1.31 & 1.31 & -1.70 & -1.65 & -1.67 \\
\hline
\end{tabular}

Notes: MG stands for Mean Group estimates and CCEMG and CCEP denote the Common Correlated Effects Mean Group and Pooled estimates respectively. The dependent variable is the logarithm of output per capita, $\ln y_{j t}$. Standard errors are given in parenthesis; for more details see Pesaran (2006). Symbols denote ${ }^{*} 10 \%,{ }^{* *} 5 \%, * * * 1 \%$ rejections.

The estimated share of capital in output, $\alpha_{1}$, and the share of oil in output, $\alpha_{2}$, vary depending on which oil variable we use in our analysis. However, it is clear from Table 5 that for the full sample in all cases $\alpha_{1}>\alpha_{2}$, and their sum is about one-third. While the estimated shares of capital and oil are very similar using oil production, $(i)$, and oil rent, (ii), the values obtained using oil reserves, (iii), are smaller for both $\alpha_{1}$ and $\alpha_{2}$. However, as previously mentioned no matter for which measure of oil we use the results indicate that the effect of oil on GDP is significantly positive.

To make sure that these results are not driven by a few countries with large coefficients on the oil variables, we look at the individual country CCEMG estimates for each of the three specifications considered. ${ }^{14}$ For the full sample, the coefficients of the investment share and the three oil variables all lie in a sensible range. There are only eight countries for which oil production has a negative effect on real income and nine countries for which oil rent has the same effect. However, this effect is only significantly negative for five countries (Chile, France, Netherlands, New Zealand, and Thailand) all of whom are net importers of oil. Thus even at the individual country level there is no evidence that oil abundance, as measured

\footnotetext{
${ }^{14}$ The results for the individual countries are not reported in the paper, but they are available upon request.
} 
by oil production and rent values, stunts development. On the other hand using oil reserves we find a significant negative effect of oil abundance on 11 out of the 53 countries in our sample ${ }^{15}$; of which only five are net exporters of oil. However, as only five out of the 30 oil exporters in our sample have a negative coefficient on oil reserves in the CCEMG estimations, overall the results of the individual country estimates suggest that oil abundance does not stunt development, thus echoing the results obtained using oil production and rent values.

Table 5: Capital and Oil Shares in CCEMG Regressions

\begin{tabular}{|l|cccc|cccc|cccc|}
\hline & \multicolumn{3}{|c|}{$(i)$} & \multicolumn{3}{c|}{$(\mathrm{ii})$} & \multicolumn{4}{c|}{$(\mathrm{iii})$} \\
$\alpha_{1}$ & All & EX & OPEC & OECD & All & EX & OPEC & OECD & All & EX & OPEC & OECD \\
\cline { 2 - 13 }$\alpha_{2}$ & 0.172 & 0.129 & 0.138 & 0.214 & 0.171 & 0.128 & 0.134 & 0.213 & 0.162 & 0.115 & $0.089^{\dagger}$ & 0.211 \\
$\alpha_{1}+\alpha_{2}$ & 0.123 & 0.183 & 0.210 & $0.000^{\dagger}$ & 0.116 & 0.184 & 0.218 & $0.002^{\dagger}$ & 0.031 & 0.052 & $0.037^{\dagger}$ & $-0.01^{\dagger}$ \\
\end{tabular}

Notes: ${ }^{\dagger}$ Symbol denotes that the coefficient is not significant in CCEMG regressions. $(i)$ is estimated by augmenting (4) with the simple cross sectional averages of the regressors using $\ln o_{j t}$, whereas $(i i)$ and $(i i i)$ are estimated in the same way but by using $\ln o r_{j t}$ and $\ln s_{j t}$ respectively. EX refers to the 30 oil exporting countries in our sample, OPEC to the Organization of the Petroleum Exporting countries, and OECD to the Organization for Economic Cooperation and Development, for further details see Table 9 .

We split the sample into three subsets: oil exporting countries (EX) and countries that are members of the Organization of the Petroleum Exporting Countries (OPEC) and the Organization for Economic Cooperation and Development (OECD) ${ }^{16}$. Re-estimating specifications $(i)$ to $($ iii $)$, using these subsets, we report in Table 5 the CCEMG estimates of the shares of oil and capital in output. For all three subsets, just like in the full sample, the estimates for $\alpha_{1}$ and $\alpha_{2}$, have the correct signs and are very similar when considering the specifications with oil rent and oil production. In addition, while $\alpha_{1}$ is significantly positive for all countries in the subsets, $\alpha_{2}$ is positive but only significant for the oil exporters and the OPEC countries.

The estimates using oil reserve data, $($ iii $)$, are however, significantly smaller for both the shares of capital and oil. While both $\alpha_{1}$ and $\alpha_{2}$ are still significantly positive for the oil exporting countries, they are positive but insignificant for the OPEC countries. Focusing on the oil rent and production specifications, we can see that while for the OECD countries $\alpha_{1}>\alpha_{2}$, this is not the case for the OPEC and EX countries for which $\alpha_{1}<\alpha_{2}$, with the value of the shares being very similar when comparing the two subsets. These results are perhaps expected for these countries since the share of oil in output is quite significant as oil production dominates economic activity for these countries. Notice also that the sum of $\alpha_{1}$ and $\alpha_{2}$ are reasonable for these two subsets being around one-third. It is also interesting to note that for the OECD countries as a group the share of oil in output is not significantly different from zero. Again we would have expected $\alpha_{2}$ to be significantly smaller for the OECD group as compared to that of the OPEC and EX countries.

To make sure that the results are not driven by a few outliers in the sub-samples, we look at country-specific estimations for the OPEC and EX countries. Overall the coefficients

\footnotetext{
${ }^{15}$ Bahrain, China, Democratic Republic of the Congo, Denmark, Egypt, France, India, Iran, Italy, Japan, and Thailand.

${ }^{16}$ Some countries belong to more than one subset.
} 
of the oil variables and the share of investment in output are reasonable. The United Arab Emirates is the only country in OPEC for which oil rent and production have a negative effect on income, but this is in fact insignificant. However, using oil reserves in our estimation, we find a significant negative effect of oil abundance on income for Iran and Nigeria. Turning to the results for the EX countries we find that there are no countries for which the coefficient of oil rent and production is significantly negative. On the other hand, using oil reserves we find that there are five countries (Bahrain, Democratic Republic of the Congo, Egypt, Iran and Nigeria) for which oil abundance has a negative effect on income. But as this is only five countries out of the 30 countries considered, the results do not seem to indicate that resource abundance harms development. Thus we can conclude that the estimates for the OPEC and the oil exporting countries do not seem to be affected by outliers and suggest that oil abundance is in fact a blessing and not a curse.

\subsubsection{Robustness Check with FMOLS Approach}

To check the robustness of our results we also estimate our model using Pedroni's group mean fully modified OLS (FMOLS) estimator. Since our data are non-stationary, this means that by using Pedroni's FMOLS for heterogeneous cointegrated panels we can potentially exploit the superconsistency properties of cointegrating systems to address inevitable biases coming from endogeneity and omitted variables while at the same time accounting for cross-sectional dependence through common time effects. ${ }^{17}$ The FMOLS group mean estimates and the corresponding standard errors are reported in Table 6. All of the coefficients are correctly signed with those of the real value of oil production and oil rent per capita statistically significant and positive. Overall Table 6 confirms the robustness of our previous results and provides evidence of the positive level effects of oil abundance.

\section{Table 6: Estimation Results 1980-2006}

\begin{tabular}{|c|c|c|c|}
\hline $\ln y_{j t}$ & \multicolumn{3}{|c|}{ Group Mean FMOLS } \\
\hline $\ln (I / Y)_{j t}$ & $\begin{array}{c}0.33^{* * * *} \\
(0.020)\end{array}$ & $\begin{array}{c}0.32^{* * * *} \\
(0.019)\end{array}$ & $\begin{array}{c}0.28^{* * * *} \\
(0.020)\end{array}$ \\
\hline $\ln o_{j t}$ & $\begin{array}{c}0.12^{* * * *} \\
(0.014)\end{array}$ & - & - \\
\hline $\ln o r_{j t}$ & - & $\begin{array}{c}0.11^{* * *} \\
(0.015)\end{array}$ & - \\
\hline $\ln s_{j t}$ & - & - & $\begin{array}{c}0.02 \\
(0.500)\end{array}$ \\
\hline$\alpha_{1}$ & 0.248 & 0.242 & 0.219 \\
\hline$\alpha_{2}$ & 0.090 & 0.083 & 0.016 \\
\hline$\alpha_{1}+\alpha_{2}$ & 0.338 & 0.325 & 0.235 \\
\hline
\end{tabular}

Notes: The estimates are based on the Pedroni (2000) group mean FMOLS estimator. The dependent variable is the logarithm of output per capita, $\ln y_{j t}$. Standard errors are given in parenthesis. Symbols denote ${ }^{*} 10 \%,{ }^{* *} 5 \%,{ }^{* * *} 1 \%$ rejections.

The shares of capital and oil in output, using the estimated coefficients, are also reported in Table 6. As before the share of capital is greater than that of oil, and the total shares, $\alpha_{1}+\alpha_{2}$, are around one-third. Comparing these results with the shares computed using the

\footnotetext{
${ }^{17}$ For further details see Pedroni (2000).
} 
CCEMG estimator, Table 5, we observe that generally the share of capital is larger and the share of oil is smaller using the group mean FMOLS estimator.

\subsection{Panel Cointegration Test Results}

We use the residuals, $\widehat{e}_{j t}$, obtained from the CCEMG estimation of

$$
\ln y_{j t}=a_{j}+d_{j} t+\beta_{j 1} \ln (I / Y)_{j t}+\beta_{j 2} \ln o_{j t}+b_{j 0} \ln \overline{y_{t}}+b_{j 1} \ln (\overline{I / Y})_{t}+b_{j 2} \ln \bar{o}_{t}+e_{j t}
$$

to test the null of no cointegration between real GDP per capita, the investment share of GDP, and three different measures for oil; namely $(i)$ the real value of oil production per capita; $(i i)$ real oil rent per capita; and ( $i i i)$ the real value of oil reserves per capita. The CCEMG estimation procedure applied in (19) asymptotically eliminates both weak as well as strong forms of cross sectional dependence in large panels. Thus our cointegration test is based on the IPS test procedure, as our goal is to determine whether the residuals, $\widehat{e}_{j t}$, contain a unit root or not. The panel cointegration test results are displayed in Table 7a and suggest rejection of the null hypothesis of no cointegration for all three specifications even at the one percent level and for all the augmentation orders, $p=0,1,2$, and 3 .

Table 7: Panel Cointegration Test Results

\begin{tabular}{|c|c|c|c|c|}
\hline \multicolumn{5}{|c|}{ (a) IPS test on residuals of CCEMG estimations } \\
\hline & $A D F(0)$ & $A D F(1)$ & $A D F(2)$ & $A D F(3)$ \\
\hline$($ i $)$ & $-3.179^{* * *}$ & $-3.063^{* * *}$ & $-2.790^{* * *}$ & $-2.688^{* * *}$ \\
\hline$($ ii $)$ & $-3.130^{* * *}$ & $-3.034^{* * *}$ & $-2.742^{* * *}$ & $-2.659^{* * *}$ \\
\hline$($ iii $)$ & $-3.193^{* * *}$ & $-3.222^{* * *}$ & $-2.966^{* * *}$ & $-2.737^{* * *}$ \\
\hline
\end{tabular}

\begin{tabular}{|c|c|c|c|c|c|c|}
\hline \multicolumn{1}{|c|}{ (b) Pedroni's test on residuals of MG estimations } \\
\hline & \multicolumn{3}{|c|}{ Raw data } & \multicolumn{3}{c|}{ Demeaned data } \\
\hline & $\rho$-statistic & PP & ADF & $\rho$-statistic & PP & ADF \\
\hline$(i)$ & $2.94^{* * *}$ & $-2.05^{* *}$ & $-4.65^{* * *}$ & $2.94^{* * *}$ & $-1.90^{*}$ & $-2.82^{* * *}$ \\
\hline$($ ii $)$ & $2.79^{* * *}$ & $-2.34^{* *}$ & $-5.10^{* * *}$ & $2.93^{* * *}$ & $-1.74^{*}$ & $-2.82^{* * *}$ \\
\hline$($ iii $)$ & $2.95^{* * *}$ & $-1.94^{* *}$ & $-3.80^{* * *}$ & $3.49^{* * *}$ & -0.98 & $-3.04^{* * *}$ \\
\hline
\end{tabular}

Notes: $\rho$-statistic, PP, and ADF columns report the Pedroni $(1999,2004)$ group mean tests for null of no cointegration. Fixed effects and heterogeneous trends have been included in all cases. Symbols denote ${ }^{*} 10 \%, * * 5 \%, * * * 1 \%$ rejections.

To check the robustness of our results we also apply Pedroni's $(1999,2004)$ tests for the null hypothesis of no cointegration to the residuals, $\widehat{u}_{j t}$ from the hypothesized cointegrating relationship in (18), but also using (ii) oil rent and ( iii) reserves measures. The three panel cointegration test statistics based on a group mean approach are reported in Table $7 \mathrm{~b}$. The first one is analogous to the Phillips and Perron $\rho$-statistic, and the other two are analogous to the Phillips and Perron t-statistic (non parametric) and the augmented Dickey-Fuller t-statistic (parametric). ${ }^{18}$ Looking at the results for the raw data, as reported in the first three columns, we see that all tests reject the null of no cointegration at the 5 percent level and in most cases even at the one percent level. When using data that have been demeaned

\footnotetext{
${ }^{18}$ For a discussion and mathematical expositions of these statistics see Pedroni (1999) and Pedroni (2004).
} 
with respect to the cross-sectional dimension for each time period ${ }^{19}$, we reject the null at the one percent level using the ADF and $\rho$-statistics. The PP test statistics on the other hand suggest rejection of the null at the 10 percent level using $(i)$ oil production and $(i i)$ rent data, but cannot reject the null using (iii) oil reserves data. Thus the results, based on both the IPS and the Pedroni tests, suggest the existence of cointegrating relationships among the variables in our model for all three specifications, $(i)$ to $(i i i)$.

\subsection{Panel Error Correction Specifications}

Having established panel cointegration between real GDP per capita, the share of investment in real GDP, and the real value of oil production per capita (as well as real value of oil reserves and real oil rent per capita), we now estimate the following panel error correction model

$$
\begin{aligned}
\Delta \ln y_{j t}= & e_{j}+\psi_{j}\left[\ln y_{j, t-1}-\chi_{j 1} \ln (I / Y)_{j, t-1}-\chi_{j 2} \ln o_{j, t-1}\right] \\
& +\kappa_{j 1} \Delta \ln (I / Y)_{j t}+\kappa_{j 2} \Delta \ln o_{j t}+\kappa_{j 3} \Delta \ln y_{j t-1}+v_{j t}
\end{aligned}
$$

to determine the short-run and the long-run effects of oil on real GDP per capita. To investigate these effects, firstly we need to consider whether $\psi_{j}$, the coefficients on $\ln y_{j, t-1}$, are statistically different from zero. If this is not the case, the cointegration results would not be reliable. Secondly, we need to test the null hypothesis that the parameter vector of the short-run response coefficients, $\boldsymbol{\kappa}_{j}=\left(\kappa_{j 1}, \kappa_{2 j}, \kappa_{j 3}\right)^{\prime}$, are equal to zero. If the null cannot be rejected, then there would be no evidence for short run dynamics. Table 8 displays the results from estimating the above equation. As before there is considerable cross sectional dependence in the MG regressions, see the first three columns. To address this issue, we computed CCEMG and CCEP estimates by augmenting (20) with simple cross sectional averages of the regressors. To check the robustness of our estimates we also estimated (20) by replacing $\ln o_{j t}$ with $\ln o r_{j t}$ and $\ln s_{j t}$. The coefficients on $\ln y_{j, t-1}$, in all specifications are statistically significant and different from zero indicating that the system reverts to the longrun values following a shock. All other estimated coefficients are correctly signed with the coefficients of the real value of oil production and rent statistically significant and positive in both the short-run and the long-run, indicating that oil abundance has both positive level and growth effects. Thus illustrating that the results of the cross-sectional specifications usually employed in the literature, as reported in Section 3, might in fact be misleading.

When estimating (20) using the real value of oil reserves instead of production, while the MG and the CCEMG estimates show statistically significant and positive coefficients for $\ln s_{j t-1}$ and $\Delta \ln s_{j t}$ the CCEP estimates although being positive are insignificant. As we believe that there is considerable heterogeneity and cross sectional dependence across countries in our sample, we focus on the CCEMG estimates, which generally has significantly larger coefficients on both the investment share of output and the oil variables considered as compared to the MG and CCEP estimates. The estimated share of capital in output, $\alpha_{1}$, and the share of oil in output, $\alpha_{2}$, vary depending on which oil variable we use in our analysis, but are in line with those reported in Table 5. As before the share of capital in

\footnotetext{
${ }^{19}$ The demeaned version serves to extract common time effects from the data and the results can be interpreted as accounting for certain forms of cross-sectional dependency.
} 
Table 8: Panel Error Correction Estimates 1980-2006

\begin{tabular}{|c|c|c|c|c|c|c|c|c|c|}
\hline$\Delta \ln y_{j t}$ & \multicolumn{3}{|c|}{ MG } & \multicolumn{3}{|c|}{ CCEMG } & \multicolumn{3}{|c|}{ CCEP } \\
\hline $\ln y_{j, t-1}$ & $\begin{array}{c}-0.39^{* * *} \\
(0.025)\end{array}$ & $\begin{array}{c}-0.39^{* * *} \\
(0.025)\end{array}$ & $\begin{array}{c}-0.37^{* * *} \\
(0.026)\end{array}$ & \begin{tabular}{|c|}
$-0.61 * * *$ \\
$(0.047)$
\end{tabular} & $\begin{array}{c}-0.59^{* * *} \\
(0.044)\end{array}$ & $\begin{array}{c}-0.55^{* * *} \\
(0.053)\end{array}$ & $\begin{array}{c}-0.32^{* * *} \\
(0.026)\end{array}$ & \begin{tabular}{|c}
$-0.32^{* * *}$ \\
$(0.026)$
\end{tabular} & $\begin{array}{c}-0.35 * * * \\
(0.033)\end{array}$ \\
\hline $\ln (I / Y)_{j, t-1}$ & $\begin{array}{c}0.07 * * * \\
(0.012)\end{array}$ & $\begin{array}{c}0.08^{* * *} \\
(0.013)\end{array}$ & $\begin{array}{c}0.08^{* * *} \\
(0.015)\end{array}$ & $\begin{array}{c}0.13^{* * *} \\
(0.021)\end{array}$ & $\begin{array}{c}0.13^{* * *} \\
(0.021)\end{array}$ & $\begin{array}{c}0.09 * * * \\
(0.026)\end{array}$ & $\begin{array}{c}0.07^{* * *} \\
(0.013)\end{array}$ & $\begin{array}{c}0.07^{* * * *} \\
(0.013)\end{array}$ & $\begin{array}{c}0.07^{* * *} \\
(0.015)\end{array}$ \\
\hline $\ln o_{j, t-1}$ & $\begin{array}{c}0.04 * * * \\
(0.010)\end{array}$ & - & - & $\begin{array}{c}0.10^{* * * *} \\
(0.027)\end{array}$ & - & - & $\begin{array}{c}0.03^{* * *} \\
(0.005)\end{array}$ & - & - \\
\hline$\Delta \ln o_{j t}$ & $\begin{array}{c}0.04^{* * *} \\
(0.011)\end{array}$ & - & - & $\begin{array}{c}0.11^{* * *} \\
(0.024)\end{array}$ & - & - & $\begin{array}{l}0.03^{* *} \\
(0.015)\end{array}$ & - & - \\
\hline $\ln o r_{j, t-1}$ & - & $\begin{array}{c}0.03^{* * *} \\
(0.008)\end{array}$ & - & - & $\begin{array}{c}0.08^{* * * *} \\
(0.025)\end{array}$ & - & - & $\begin{array}{c}0.03^{* * *} \\
(0.005)\end{array}$ & - \\
\hline$\Delta \ln o r_{j t}$ & - & $\begin{array}{c}0.03^{* * *} \\
(0.010)\end{array}$ & - & - & $\begin{array}{c}0.11^{* * *} \\
(0.025)\end{array}$ & - & - & $\begin{array}{l}0.03^{* *} \\
(0.015)\end{array}$ & - \\
\hline $\ln s_{j, t-1}$ & - & - & $\begin{array}{l}0.02^{* * *} \\
(0.006)\end{array}$ & - & - & $\begin{array}{l}0.04^{* *} \\
(0.017)\end{array}$ & - & - & $\begin{array}{l}0.002 \\
(0.004)\end{array}$ \\
\hline$\Delta \ln s_{j t}$ & - & - & $\begin{array}{c}0.02^{* * *} \\
(0.006)\end{array}$ & - & - & $\begin{array}{l}0.02^{*} \\
(0.012)\end{array}$ & - & - & $\begin{array}{c}0.002 \\
(0.003)\end{array}$ \\
\hline$\Delta \ln (I / Y)_{j t}$ & $\begin{array}{c}0.13^{* * *} \\
(0.019)\end{array}$ & $\begin{array}{c}0.13^{* * *} \\
(0.019)\end{array}$ & $\begin{array}{c}0.14^{* * * *} \\
(0.022)\end{array}$ & $\begin{array}{c}0.15^{* * *} \\
(0.021)\end{array}$ & $\begin{array}{c}0.15^{* * *} \\
(0.021)\end{array}$ & $\begin{array}{c}0.12^{* * *} \\
(0.025)\end{array}$ & $\begin{array}{c}0.07^{* * *} \\
(0.011)\end{array}$ & $\begin{array}{c}0.07^{* * *} \\
(0.011)\end{array}$ & $\begin{array}{c}0.08^{* * * *} \\
(0.012)\end{array}$ \\
\hline$\Delta \ln y_{j, t-1}$ & $\begin{array}{c}0.17^{* * *} \\
(0.032)\end{array}$ & $\begin{array}{c}0.17^{* * *} \\
(0.032) \\
\end{array}$ & $\begin{array}{c}0.13^{* * * *} \\
(0.035) \\
\end{array}$ & $\begin{array}{l}0.09^{* *} \\
(0.038) \\
\end{array}$ & $\begin{array}{l}0.08^{* *} \\
(0.038)\end{array}$ & $\begin{array}{c}0.12^{* * *} \\
(0.044) \\
\end{array}$ & $\begin{array}{c}0.10^{* * *} \\
(0.050) \\
\end{array}$ & $\begin{array}{l}0.11^{* *} \\
(0.051)\end{array}$ & $\begin{array}{l}0.11^{* *} \\
(0.052)\end{array}$ \\
\hline CD Test Statistics & 4.97 & 5.09 & 4.04 & -0.84 & -0.90 & -1.51 & -1.40 & -1.39 & -0.49 \\
\hline
\end{tabular}

Notes: The country specific intercepts are estimated but not reported. MG stands for Mean Group estimates while CCEMG and CCEP denote the Common Correlated Effects Mean Group and Pooled estimates respectively. The dependent variable is the change in the logarithm of output per capita, $\Delta \ln y_{j t}$. Standard errors are given in parenthesis. Symbols denote $* 10 \%$, $* * 5 \%, * * * 1 \%$ rejections.

output is larger than the share of oil in output and they sum to less than one-third. The coefficients of the short-run parameters suggest an elasticity of real income with respect to both production and rent per capita of around 11 percent, with the reserve elasticity of income at two percent. Our results then seem to confirm that oil abundance has both a positive level (long-run) as well as growth (short-run) effects.

To check the robustness of our results to the choice of natural resource considered, we performed the same estimations with the three measures of $(i)$ real value of production, $(i i)$ rent, and ( iii) reserves per capita but by using natural gas as well as combining natural gas and oil data and obtained very similar results to the ones reported in Tables 4 and 8 . For the sake of space, these results are not reported but are available upon request.

\section{Concluding Remarks}

This paper has re-visited the resource curse paradox in a panel made up of 53 countries over 27 years. The sample covered 85 percent of world GDP, 77 percent of world oil production per day, and 81 percent of world proven oil reserves and exhibited a substantial degree of cross country heterogeneity. We started off by developing a theory consistent econometric model, which suggested a long run relationship between the variables in our model. We then employed the Common Correlated Effects type estimators developed in Pesaran (2006) to test whether natural resource abundance is a curse or a blessing, and also contrasted these results with those of Pedroni's FMOLS approach.

Using the Cross-section Dependence (CD) test of Pesaran (2004) we were able to establish 
that the variables in our model in fact exhibit considerable cross sectional dependence. Due to the presence of this cross sectional dependence, we employed Pesaran's CIPS test to determine whether these variables are non-stationary or not. Having established that they are, we tested the effects of the real value of: $(i)$ oil production, $(i i)$ rent, and $(i i i)$ reserve on real income. We mainly relied on the CCEMG estimates as they explicitly take into account both cross sectional dependence and cross country heterogeneity among the countries in our sample. The results suggested that the effect of oil abundance on real income is significantly positive. In addition, the CCEMG estimates suggested that the share of capital in output, $\alpha_{1}$, is larger than the share of oil in output, $\alpha_{2}$, with their sum being about one-third. To ensure that the results are not affected by outliers we looked at the individual country estimates and were able to confirm that the coefficients of the investment share and the three oil variables are all sensible and in line with the full sample estimations. As a further robustness check we estimated our model using Pedroni's group mean fully modified OLS (FMOLS) estimator and obtained very similar results. In addition, we performed cointegration tests, using the IPS methodology as well as Pedroni's cointegration tests, and were able to reject the null of no cointegration for all the specifications considered, providing empirical support for the theory derived long-run relationship between the variables in our model.

We also estimated separate models for oil exporters as a whole, as well as for the OPEC and OECD countries, and confirmed that in all three subsets, oil abundance has a positive effect on real income. It is interesting to note that while $\alpha_{1}>\alpha_{2}$ for the OECD countries, the opposite is true for the oil exporting countries. We would expect this result for the oil exporting countries (both the EX and the OPEC subsets), as the share of oil in real GDP is very large because oil production dominates economic activity for these countries.

To determine the short-run effects of oil abundance, we also estimated a panel error correction model. All of the estimated oil variable coefficients, using (i) to ( $i i i)$, are positively signed and statistically significant, thus indicating that oil abundance has short-run growth enhancing effects. Moreover, the shares of oil and capital in output are in line with what is expected and the elasticity of oil in income is around 11 percent when using oil production and rent as a proxy for resource abundance, while only being around two percent when using oil reserves. In general, the estimates using oil reserves, although statistically significant and positive, are weaker that the ones using oil production and rent. We argue that the flow measures are better indicators of abundance as they portrait a country's ability to extract its stock and make use of the proceeds. Our results thus show that oil abundance is in fact a blessing and not a curse, both for the short- (growth effects) and long- (level effects) run. 


\section{References}

Anderson, T. W. and C. Hsiao (1981). Estimation of Dynamic Models with Error Components. Journal of the American Statistical Association 76(375), 598-606.

Anderson, T. W. and C. Hsiao (1982). Formulation and Estimation of Dynamic Models Using Panel Data. Journal of Econometrics 18(1), 47-82.

Arellano, M. and S. Bond (1991). Some Tests of Specification for Panel Data: Monte Carlo Evidence and an Application to Employment Equations. The Review of Economic Studies 58(2), 277-297.

Arellano, M. and O. Bover (1995). Another Look at the Instrumental Variable Estimation of Error-components Models. Journal of Econometrics 68(1), 29-51.

Arezki, R. and F. van der Ploeg (2007). Can the Natural Resource Curse be Turned into a Blessing? The Role of Trade Policies and Institutions. CEPR Discussion Paper 6225.

Boschini, A., J. Pettersson, and J. Roine (2007). Resource Curse or Not: A Question of Appropriability. Scandinavian Journal of Economics 109(3), 593-617.

Bravo-Ortega, C., J. De Gregorio, and D. Paraguay (2005). The Relative Richness of the Poor? Natural Resources, Human Capital, and Economic Growth. The World Bank: Policy Research Working Paper Series 3484.

Brunnschweiler, C. N. (2009). Oil and Growth in Transition Countries. Center of Economic Research at ETH Zurich Working Paper 09/108.

Brunnschweiler, C. N. and E. H. Bulte (2008). The Resource Curse Revisited and Revised: A Tale of Paradoxes and Red Herrings. Journal of Environmental Economics and Management 55(3), 248-264.

Bulte, E. H., R. Damania, and R. T. Deacon (2005). Resource Intensity, Institutions, and Development. World Development 33(7), 1029-1044.

Caselli, F. and T. Cunningham (2009). Leader Behaviour and the Natural Resource Curse. Oxford Economic Papers Forthcoming.

Collier, P. and A. Hoeffler (2004). Greed and Grievance in Civil War. Oxford Economic Papers 56, 563-595.

Corden, W. M. and J. P. Neary (1982). Booming Sector and De-Industrialisation in a Small Open Economy. The Economic Journal 92(368), 825-848.

Dasgupta, P. and G. Heal (1974). The Optimal Depletion of Exhaustible Resources. The Review of Economic Studies 41, 3-28.

Durlauf, S. and D. Quah (1999). The New Empirics of Growth. In J. Taylor and M. Woodfern (Eds.), Handbook of Macroeconomics, pp. 235-308. North-Holland. 
Durlauf, S. N., P. A. Johnson, and J. R. Temple (2005). Chapter 8 Growth Econometrics. Volume 1 of Handbook of Economic Growth, pp. 555 - 677. Elsevier.

Durlauf, S. N., P. A. Johnson, and J. R. W. Temple (2009). The Methods of Growth Econometrics. Volume 2 of Palgrave Handbook of Econometrics. Palgrave Macmillan.

Esfahani, H. S., K. Mohaddes, and M. H. Pesaran (2009). Oil Exports and the Iranian Economy. Cambridge Working Papers in Economics 0944.

Gylfason, T. (2001). Natural Resources, Education, and Economic Development. European Economic Review 45(4-6), 847-859.

Gylfason, T., T. T. Herbertsson, and G. Zoega (1999). A Mixed Blessing. Macroeconomic Dynamics 3(02), 204-225.

Henry, P. B. (2007). Capital Account Liberalization: Theory, Evidence, and Speculation. Journal of Economic Literature 45, 887-935.

Holly, S., M. Pesaran, and T. Yamagata (2009). A Spatio-Temporal Model of House Prices in the US. Journal of Econometrics Forthcoming.

Im, K. S., M. H. Pesaran, and Y. Shin (2003). Testing for Unit Roots in Heterogeneous Panels. Journal of Econometrics 115(1), 53-74.

Kapetanios, G., M. H. Pesaran, and T. Yamagata (2006). Panels with Nonstationary Multifactor Error Structures. Cambridge Working Papers in Economics 0651.

Klenow, P. and A. Rodriguez-Clare (1997). The Neoclassical Revival in Growth Economics: Has it Gone Too Far? In NBER Macroeconomics Annual 1997, Volume 12, pp. 73-103. MIT Press.

Krugman, P. (1987). The Narrow Moving Band, the Dutch Disease, and the Competitive Consequences of Mrs. Thatcher: Notes on Trade in the Presence of Dynamic Scale Economies. Journal of Development Economics 27(1-2), 41-55.

Lane, P. R. and A. Tornell (1996). Power, Growth, and the Voracity Effect. Journal of Economic Growth 1, 213-241.

Lee, K., M. H. Pesaran, and R. Smith (1997). Growth and Convergence in a Multi-Country Empirical Stochastic Solow Model. Journal of Applied Econometrics 12(4), 357-392.

Lee, K., M. H. Pesaran, and R. Smith (1998). Growth Empirics: A Panel Data Approach - A Comment. The Quarterly Journal of Economics 113(1), 319-323.

Leite, C. and M. Weidmann (1999). Does Mother Nature Corrupt? Natural Resources,. Corruption and Economic Growth. IMF Working Paper 9985.

Mehlum, H., K. Moene, and R. Torvik (2006). Institutions and the Resource Curse. The Economic Journal 116, 1-20. 
Neary, J. P. and S. J. G. van Wijnbergen (1986). Natural Resources and the Macroeconomy. MIT Press, Cambridge, MA.

Pedroni, P. (1999). Critical Values for Cointegration Tests in Heterogeneous Panels with Multiple Regressors. Oxford Bulletin of Economics and Statistics 61, 653-670.

Pedroni, P. (2000). Fully Modified OLS for Heterogeneous Cointegrated Panels. In Advances in Econometrics: Nonstationary Panels, Panel Cointegration and Dynamic Panels, Volume 15, pp. 93-130. Emerald Group Publishing Limited.

Pedroni, P. (2004). Panel Cointegration: Asymptotic and Finite Sample Properties of Pooled Time Series Tests with an Application to the PPP Hypothesis. Econometric Theory $20(03), 597-625$.

Pedroni, P. (2007). Social Capital, Barriers to Production and Capital Shares: Implications for the Importance of Parameter Heterogeneity from a Nonstationary Panel Approach. Journal of Applied Economics 22, 429-451.

Pesaran, M. H. (2004). General Diagnostic Tests for Cross Section Dependence in Panels. CESifo Working Paper 1229.

Pesaran, M. H. (2006). Estimation and Inference in Large Heterogeneous Panels with a Multifactor Error Structure. Econometrica 74 (4), 967-1012.

Pesaran, M. H. (2007). A Simple Panel Unit Root Test in the Presence of Cross-section Dependence. Journal of Applied Econometrics 22, 265-312.

Pesaran, M. H. and R. Smith (1995). Estimating Long-run Relationships from Dynamic Heterogeneous Panels. Journal of Econometrics 68(1), 79-113.

Pesaran, M. H. and E. Tosetti (2007). Large Panels with Common Factors and Spatial Correlations. CESifo Working Paper 2103.

Rodriguez, F. and J. D. Sachs (1999). Why Do Resource-Abundant Economies Grow More Slowly? Journal of Economic Growth 4, 277-303.

Rosser, A. (2006). The Political Economy of the Resource Curse: A Literature Survey. Institute of Development Studies Working Paper 268.

Sachs, J. D. and A. M. Warner (1995). Natural Resource Abundance and Economic Growth. National Bureau of Economic Research Working Paper 5398.

Sachs, J. D. and A. M. Warner (1997). Sources of Slow Growth in African Economies. Journal of African Economies 6(3), 335-376.

Sachs, J. D. and A. M. Warner (2001). The Curse of Natural Resources. European Economic Review 45(4-6), 827-838.

Stiglitz, J. (1974a). Growth with Exhaustible Natural Resources: Efficient and Optimal Growth Paths. The Review of Economic Studies 41, 123-137. 
Stiglitz, J. E. (1974b). Growth with Exhaustible Natural Resources: The Competitive Economy. The Review of Economic Studies 41, 139-152.

Stijns, J.-P. C. (2005). Natural Resource Abundance and Economic Growth Revisited. Resources Policy 30(2), 107-130.

Tornell, A. and P. R. Lane (1999). The Voracity Effect. The American Economic Review $89(1), 22-46$.

van der Ploeg, R. and T. Venables (2009). Symposium on Resource Rich Economies Introduction. Oxford Economic Papers Forthcoming. 


\section{Appendix A: Proof of Proposition 1}

We consider a particular equilibrium path in which the control, state and costate variables grow at a constant rate, and we will show that this equilibrium exists. Using the Euler equation (7), and given that along the balanced growth path the growth rate of consumption is constant, it must be that the growth rate of output is equal to the growth rate of the capital stock: $g_{Y}^{*}=g_{K}^{*}$. Let's guess that $\gamma^{*}$ is constant, such that $g_{\gamma}^{*}=0$, but given this and (12):

$$
g_{S}^{*}=-\gamma^{*}+\frac{I^{S}}{S}
$$

$\frac{I^{S}}{S}$ must then be constant. This implies that $q^{S}=1+\phi\left(\frac{I^{S}}{S}\right)+\phi^{\prime}\left(\frac{I^{S}}{S}\right) \frac{I^{S}}{S}$ is constant and from (8) and (6), we have that $g_{\lambda}^{*}=g_{\mu}^{*}=-\left(\rho+\theta g_{c}^{*}\right)$. Next, taking the log derivatives of (9) we get:

$$
g_{\lambda}^{*}+g_{Y}^{*}-g_{\gamma}^{*}-g_{S}^{*}=g_{\mu}^{*} \Rightarrow g_{Y}^{*}-g_{\gamma}^{*}-g_{S}^{*}=0,
$$

but since $g_{\gamma}^{*}=0$, the above implies that $g_{Y}^{*}=g_{S}^{*}$. Therefore, from the production function, (1), we have that:

$$
g_{K}^{*}=g_{Y}^{*}=g_{S}^{*}=n+g .
$$

Rewriting the resource constraint, (11), as:

$$
\frac{N c}{Y}+\frac{\dot{K}}{K} \frac{K}{Y}+\frac{I^{S}}{S} \frac{S}{Y}\left[1+\phi\left(\frac{I^{S}}{S}\right)\right]=1-\delta \frac{K}{Y},
$$

and given that $\frac{K}{Y}, \frac{S}{Y}, \frac{I^{S}}{S}$, and $\frac{\dot{K}}{K}$ are all constants, we have that: $g_{c}^{*}=g$.

Now it remains to show that $\gamma^{*}$ is constant and positive. From (6), (8), (10) and given that $g_{\lambda}^{*}=g_{\mu}^{*}$ we have:

$$
\left[1+\phi\left(\frac{I^{S}}{S}\right)+\phi^{\prime}\left(\frac{I^{S}}{S}\right) \frac{I^{S}}{S}\right](\rho+\theta g)=\phi^{\prime}\left(\frac{I^{S}}{S}\right)\left(\frac{I^{S}}{S}\right)^{2}
$$

From the above equation we can define $\frac{I^{S}}{S}=H(\rho+\theta g)$ as an implicit function, $H(\cdot)$, of $\rho+\theta g$. It has a unique positive solution with $\frac{I^{S}}{S}>(\rho+\theta g)$. In order to see this, observe that the right hand side of the above equation is an increasing function of $\frac{I^{S}}{S}$ that crosses the $y$-axis at the origin. The left hand side is also an increasing function of $\frac{I^{S}}{S}$, but it crosses the $y$-axis at $\rho+\theta g$. Moreover, at $\frac{I^{S}}{S}=(\rho+\theta g)$ the left hand side is larger than the right hand side. Finally, the slope of the left hand side is smaller than the slope of the right hand side for any $\frac{I^{S}}{S}>(\rho+\theta g)$. Therefore, the left hand side crosses (from above) the right hand side in only one point. Since the transversality condition requires that:

$$
\rho+\theta g>n+g
$$

we have that

$$
\gamma^{*}=H(\rho+\theta g)-(n+g)>0
$$


which verifies our guess. For instance, if we assume that $\phi\left(\frac{I^{S}}{S}\right)=\left(\frac{I^{S}}{S}\right)$, then

$$
\left(\frac{I^{S}}{S}\right)^{*}=(\rho+\theta g) \pm \sqrt{(\rho+\theta g)^{2}+(\rho+\theta g)},
$$

with a positive and a negative root. The positive root, $\left(\frac{I^{S}}{S}\right)_{+}^{*}$ is larger than $(\rho+\theta g)$. Therefore,

$$
\gamma^{*}=\left(\frac{I^{S}}{S}\right)_{+}^{*}-(n+g),
$$

is a positive constant, as required.

Given that $\phi^{\prime}(\cdot)>0, \phi^{\prime \prime}(\cdot) \geq 0,\left(\frac{I^{S}}{S}\right)_{+}^{*}>0$, and $\phi\left(\left(\frac{I^{S}}{S}\right)_{+}^{*}\right)>0, q^{S}$ must be positive. Rewriting (9) as:

$$
\lambda \alpha_{2} \frac{Y^{*}}{O^{*}}=\mu \Rightarrow \frac{\widetilde{o}^{*}}{\widetilde{y}^{*}}=\alpha_{2} \frac{\lambda}{\mu}=\frac{\alpha_{2}}{q^{S}}>0,
$$

where $\tilde{x}$ is the intensive from of $X$ and defined by $\tilde{x}=\frac{X}{e^{g_{X}^{*}}}$, in which $g_{X}^{*}$ is the growth rate of variable $X$ in the balanced growth path, and (7) as:

$$
\rho+\theta \frac{\dot{c}}{c}=\alpha_{1} \frac{Y^{*}}{K^{*}}-\delta \Rightarrow \frac{\widetilde{k}^{*}}{\widetilde{y}^{*}}=\frac{\alpha_{1}}{\rho+\theta g+\delta}>0,
$$

and writing the production function (1) in intensive form:

$$
\widetilde{y}^{*}=\left(\frac{\widetilde{k}^{*}}{\widetilde{y}^{*}}\right)^{\frac{\alpha_{1}}{1-\alpha_{1}-\alpha_{2}}}\left(\frac{\widetilde{o}^{*}}{\widetilde{y}^{*}}\right)^{\frac{\alpha_{2}}{1-\alpha_{1}-\alpha_{2}}}
$$

it is obvious that $\widetilde{y}^{*}>0$. But this implies that both $\widetilde{o}^{*}$ and $\widetilde{k}^{*}$ are positive, and since $\gamma^{*}$ is positive, it in turn means that $\widetilde{o}^{*}=\gamma^{*} \widetilde{s}^{*}>0$. This proves part 1 of proposition 1.

The system of equations that describes the equilibrium dynamics is given by:

$$
\begin{aligned}
\dot{\tilde{c}} & =\frac{1}{\theta}\left[\alpha_{1} \tilde{k}^{\alpha_{1}-1}(\gamma \tilde{s})^{\alpha_{2}}-(\delta+\rho+\theta g)\right] \tilde{c} \\
\dot{\tilde{k}} & =\tilde{k}^{\alpha_{1}}(\gamma \tilde{s})^{\alpha_{2}}-(\delta+n+g) \tilde{k}-\tilde{c}-\frac{\tilde{\imath}^{S}}{\tilde{s}}\left(1+\phi\left(\frac{\tilde{\imath}^{S}}{\tilde{s}}\right)\right) \tilde{s}, \\
\dot{\tilde{s}} & =\left[\frac{\tilde{\imath}^{S}}{\tilde{s}}-(\gamma+n+g)\right] \tilde{s} .
\end{aligned}
$$

Moreover, $p=q$, which implies that

$$
1+\phi\left(\frac{\tilde{\tau}^{S}}{\tilde{s}}\right)+\phi^{\prime}\left(\frac{\tilde{\tau}^{S}}{\tilde{s}}\right) \frac{\tilde{\imath}^{S}}{\tilde{s}}=p .
$$

When $p$ is determined in the international market, then variable $\tilde{z}=\frac{\tilde{\tau}^{S}}{\tilde{s}}$ is independent of $\tilde{c}, \tilde{k}$, and $\tilde{s}$. Moreover, $\gamma \tilde{s}=\left(\frac{\alpha_{2}}{p}\right)^{\frac{1}{1-\alpha_{2}}} \tilde{k}^{\frac{\alpha_{1}}{1-\alpha_{2}}}$. Using $\tilde{z}$ and $\gamma \tilde{s}$ in this system and taking the 
first-order Taylor approximation around the steady-state, we have:

$$
\left(\begin{array}{c}
\dot{\tilde{c}} \\
\dot{\tilde{k}} \\
\dot{\tilde{s}}
\end{array}\right) \approx\left(\begin{array}{ccc}
0 & -\left(1-\alpha_{1}\right) \frac{(\delta+\rho+\theta g) \tilde{c}^{*}}{\theta \tilde{k}^{*}} & 0 \\
-1 & (\delta+\rho+\theta g)-(\delta+n+g) & -\tilde{z}(1+\phi(\tilde{z})) \\
0 & \frac{\alpha_{1}}{1-\alpha_{2}} \frac{\gamma^{*} \tilde{\tilde{s}}^{*}}{\tilde{k}^{*}} & \gamma^{*}
\end{array}\right)\left(\begin{array}{c}
\widetilde{c}-\widetilde{c}^{*} \\
\widetilde{k}-\widetilde{k}^{*} \\
\widetilde{s}-\widetilde{s}^{*}
\end{array}\right) .
$$

The determinant of the matrix of partial derivative is $-\left(1-\alpha_{1}\right) \frac{(\delta+\rho+\theta g) \tilde{c}^{*}}{\theta \tilde{k}^{*}} \gamma^{*}<0$. The trace of this matrix is $(\rho+\theta g)-(n+g)+\gamma^{*}$, and it is positive to satisfy the transversality conditions. These two results imply that one eigenvalue is negative, while the other two are positive, which completes the proof.

\section{Appendix B: Sources and Construction of the Data}

Our data set is balanced and contains data from the World Bank on the values of oil production and oil rent for all of the 53 countries reported in Table 9.

Table 9: Countries Included in the Sample

\begin{tabular}{|c|c|c|c|}
\hline \multicolumn{2}{|l|}{ Oil Exporters } & OECD & All other Countries \\
\hline Algeria* & Kuwait* & Australia & China \\
\hline Argentina & Malaysia & Austria & Cote d'Ivoire \\
\hline Bahrain & Mexico & Canada & India \\
\hline Bolivia & Nigeria* & Denmark & Israel \\
\hline State of Brunei Darussalam & Norway & France & Morocco \\
\hline Cameroon & Oman & Germany & Romania \\
\hline Canada & Papua New Guinea & Greece & Thailand \\
\hline Colombia & Qatar* & Hungary & \\
\hline Democratic Republic of the Congo & Saudi Arabia* & Italy & \\
\hline Republic of the Congo & Syria & Japan & \\
\hline Ecuador* & Trinidad and Tobago & Mexico & \\
\hline Egypt & Tunisia & Netherlands & \\
\hline Gabon & United Arab Emirates* & New Zealand & \\
\hline Indonesia* & United Kingdom & Norway & \\
\hline $\operatorname{Iran}^{*}$ & Venezuela* & Turkey & \\
\hline & & United Kingdom & \\
\hline & & United States & \\
\hline
\end{tabular}

Notes: * Indicate countries that are members of the Organization of the Petroleum Exporting Countries (OPEC). Oil reserve data is not available for Hungary and as such it is excluded from the estimations with $\ln s_{j t}$. OECD refers to the Organization for Economic Cooperation and Development

Oil reserve data is available for all of the countries in our data set, except for Hungary for which data is available only from 1992, from the Energy Information Administration, Department of Energy, USA. The data on GDP for all countries is obtained from the World Bank, but is not available for Bahrain (2006), for which we obtain the 2006 GDP figure by applying the growth rate of GDP in 2006 from the Central Bank of Bahrain. GDP data is also missing for Kuwait (1990-1994) so we obtain the missing data by splicing the GDP series from the Penn World Table. Finally the World Bank does not have GDP or gross capital formation for Qatar until 2000, so we use the Penn World Table data until then and obtain data for the later years by splicing the World Bank data. Our main source for data on gross fixed capital formation is the World Bank, but data is missing for Argentina (1980-1992), 
Colombia (2000-2006), and Oman (1983-1989) but available from the IMF IFS database and so we make use of that instead. Gross fixed capital formation data is also missing for Brunei (1980-1988) and Romania (1980, 1983-1989), but as this is not available from the IMF, it is obtained by splicing the data from the Penn World Table.

\section{Table 10: List of Variables and their Sources}

\begin{tabular}{|l|l|l|}
\hline$y_{j t}$ & GDP per capita (Constant 2000 US\$) & The World Bank \\
\hline$(I / Y)_{j t}$ & Gross fixed capital formation (\% of GDP) & The World Bank \\
\hline$o_{j t}$ & Real value of oil production per capita (Constant 2000 US\$) & The World Bank \\
\hline$o r_{j t}$ & Real oil rent per capita (Constant 2000 US\$) & The World Bank \\
\hline$s_{j t}$ & Real value of oil reserves per capita (Constant 2000 US $\$$ ) & Energy Information Administration \\
\hline$p_{t}^{o}$ & Oil prices (Constant 2000 US\$) & British Petroleum \\
\hline$d_{U S, t}$ & US GDP Deflator (2000=100) & The World Bank \\
\hline
\end{tabular}

Notes: Annual data between 1980 and $2006(T=27)$ for 53 Countries $(N=53)$, except for oil reserves for which we only have data for 52 countries (Hungary is excluded from this sample). 